\title{
Article \\ Microstructural, Mechanical and Physical Assessment of Portland Cement Concrete Pavement Modified by Sodium Acetate under Various Curing Conditions
}

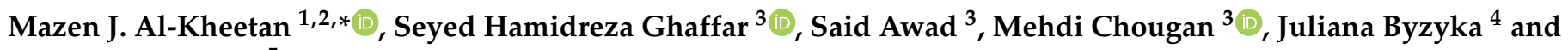 \\ Mujib M. Rahman ${ }^{5}$ \\ 1 Civil and Environmental Engineering Department, College of Engineering, Mutah University, Mutah, \\ Karak 61710, Jordan \\ 2 Materials Science and Energy Lab, MSEL, Mutah University, Mutah, Karak 61710, Jordan \\ 3 Department of Civil and Environmental Engineering, College of Engineering, Design and Physical Sciences, \\ Brunel University London, Kingston Ln, Uxbridge, Middlesex UB8 3PH, UK; \\ seyed.ghaffar@brunel.ac.uk (S.H.G.); said.awad@brunel.ac.uk (S.A.); mehdi.chougan2@brunel.ac.uk (M.C.) \\ 4 Civil Engineering Department, School of Science, Engineering and Environment, University of Salford, \\ Newton Building, Crescent, Salford M5 4NT, UK; j.byzyka@salford.ac.uk \\ 5 Department of Civil Engineering, School of Engineering and Applied Science, Aston University, Aston St, \\ Birmingham B4 7ET, UK; m.rahman19@aston.ac.uk \\ check for \\ updates \\ * Correspondence: mazen.al-kheetan@mutah.edu.jo; Tel.: +962-797-843-417
}

Citation: Al-Kheetan, M.J.; Ghaffar, S.H.; Awad, S.; Chougan, M.; Byzyka, J.; Rahman, M.M. Microstructural, Mechanical and Physical Assessment of Portland Cement Concrete Pavement Modified by Sodium Acetate under Various Curing Conditions. Infrastructures 2021, 6, 113. https://doi.org/10.3390/ infrastructures6080113

Academic Editors: Luca

Bianchini Ciampoli, Fabio Tosti and Fabrizio D'Amico

Received: 13 July 2021

Accepted: 11 August 2021

Published: 12 August 2021

Publisher's Note: MDPI stays neutral with regard to jurisdictional claims in published maps and institutional affiliations.

Copyright: (C) 2021 by the authors Licensee MDPI, Basel, Switzerland. This article is an open access article distributed under the terms and conditions of the Creative Commons Attribution (CC BY) license (https:/ / creativecommons.org/licenses/by/ $4.0 /)$.

\begin{abstract}
Portland Cement Concrete (PCC) pavement was studied with incorporation of an environmentally friendly eco-additive, sodium acetate $\left(\mathrm{C}_{2} \mathrm{H}_{3} \mathrm{NaO}_{2}\right)$. This additive was added to PCC pavement in three different percentages of $2 \%, 4 \%$ and $6 \%$ of binder weight. For a comprehensive elucidation of the eco-additive incorporation on the performance of PCC pavement, casted samples were cured in three different environments, namely: water, outdoors and pond water. Water absorption tests, flexural and compressive strength tests after 7 and 28 days of curing were conducted and results compared with the control samples without any addition of sodium acetate. Results demonstrated a significant improvement in the impermeability, compressive strength and flexural strength of PCC pavement when sodium acetate concrete is cured in a water bath and outdoors. However, no/little improvement in the impermeability, compressive strength and flexural strength was observed in sodium acetate samples that were cured in pond water. Microstructural analysis of treated samples by using scanning electron microscopy (SEM) illustrated the strengthening effect that sodium acetate provides to the pore structure of concrete pavement.
\end{abstract}

Keywords: sodium acetate; eco-friendly additives; concrete pavement; $\mathrm{C}_{2} \mathrm{H}_{3} \mathrm{NaO}_{2}$; sustainable construction; morphology

\section{Introduction}

Pavement construction and design have seen significant development in the past few years in terms of enhanced properties, less required maintenance procedures and cost efficiency [1]. However, the environmental repercussions that result from pavement construction have been barely considered by the industry and research communities [2,3].

In the past decade, more research has started to consider the environmental impacts of highway construction, which has revealed its vulnerability and the potential risks from its degradation with time [2]. Therefore, sustainable construction and green design of pavement have come to the forefront of ways to reduce greenhouse gas emissions, reduce resources exhaustion and increase the use of sustainable construction materials [4]. Accordingly, employing environmentally-friendly, bio-waste and by-products in the pavement construction material has become one of the most preferred strategies in line with sustainable development goals [5]. 
Portland cement concrete (PCC) pavement is widely used around the world in constructing roadways and highways due to its long service-life and low maintenance cost compared to asphalt pavement [6-9]. However, the presence of environmentally-unfriendly material like Portland cement as the main constituent in its composition is considered a significant disadvantage from the sustainable development perspective [10]. The production of Portland cement is responsible for more than $7 \%$ of the total $\mathrm{CO}_{2}$ emissions in the world, which has led researchers to explore other environmentally-friendly materials to partially replace cement and reduce its impact on the environment [11-17]. However, any pavement produced by replacement of cement with other materials must, at least, meet the properties of the original PCC to ensure the production of concrete with satisfactory mechanical and physical properties, especially under harsh conditions.

Many materials have been used as alternatives to Portland cement either for the purpose of full or partial replacement for enhancing cementitious composites' properties and at the same time reduce the negative impact on the environment. Fly ash, geopolymers, nanosilica, nanographite and many other materials were used as substitutes or additives for cementitious composites in pursuit of sustainable development [5,10,18-22]. Moreover, these supplementary cementitious materials have been used in order to reduce the deterioration rate and extend the service-life of concrete and/or mortar. One of these materials that was considered in authors' previous research is $\mathrm{C}_{2} \mathrm{H}_{3} \mathrm{NaO}_{2}$, commonly known as sodium acetate $[3,8,23]$. Sodium acetate is an environmentally-friendly material that has shown promising results when mixed with cement $[3,8,24-26]$. It was proven that sodium acetate is safe for the environment as it is a biodegradable material and does not include chloride in its composition [27] and adding sodium acetate to cementitious composite materials leads to an enhancement in the durability and reduction of degradation rates [23]. Previous studies revealed that adding sodium acetate to concrete with low w/c ratios (below 0.40 ) would increase the compressive strength by more than $60 \%$ and reduce the permeability by more than $70 \%[3,8,23]$. However, further research is necessary in order to assess the performance of this material when cementitious composite materials are subject to various harsh curing and environmental conditions.

Accordingly, the objectives of this study were to: (1) assess the feasibility and expedience of using such eco-friendly additive in PCC pavement, (2) investigate the influence of sodium acetate on concrete pavement when cured under different conditions, (3) check the strength development of concrete pavement subject to water, outdoor and pond water curing, and (4) investigate the morphology and interaction mechanism between concrete pavement and sodium acetate.

\section{Materials and Test Methods}

\subsection{Materials and Sample Preparations}

M5 class mortar with the composition, by mass, of 1:2:0.4 of cement, sand and water respectively, was produced following the requirements of EN 998-2 [28]. CEM II/32.5 N (sulphates $<3.5 \%$, chlorides $<0.10 \%$, and initial setting time of $1.25 \mathrm{~h}$ ) and sharp silica sand with uniform grain size distribution between $1 \mathrm{~mm}$ and $300 \mu \mathrm{m}$ were used to prepare the mix. All samples of mortar were produced with water to cement ratio $(\mathrm{w} / \mathrm{c})$ of 0.40 . The eco-friendly additive (sodium acetate $\left(\mathrm{C}_{2} \mathrm{H}_{3} \mathrm{NaO}_{2}\right)$ ) was added in ratios of $2 \%, 4 \%$ and $6 \%$ based on the weight of cement. A control mix with $0 \%$ sodium acetate was also produced for comparison reasons.

A total of 72 prisms with dimensions of $40 \mathrm{~mm} \times 40 \mathrm{~mm} \times 160 \mathrm{~mm}$ were prepared. Eighteen prisms were produced as control mixes, 18 prisms with $2 \%$ sodium acetate, 18 prisms with $4 \%$ sodium acetate, and 18 prisms with $6 \%$ sodium acetate. All prisms were left to set for 24-48 $\mathrm{h}$ before curing under three conditions: (1) in a water bath with a temperature of $17^{\circ} \mathrm{C}$, (2) in a natural environment (outdoors) where the temperature and humidity were recorded on hourly basis (Table 1), and (3) in pond water where water was collected from a pond located on the Brunel University London campus and placed in a bath with a temperature of $17^{\circ} \mathrm{C}$. The aim from pond water curing is to examine the 
performance of concrete pavement integrated with eco-friendly additive, when exposed to harsh environment that contains impurities/algae. All samples were cured for 7 and 28 days before testing.

Table 1. Average 7 and 28 days recorded temperature and humidity for samples cured in natural environment (outdoor).

\begin{tabular}{ccccc}
\hline \multirow{2}{*}{$\begin{array}{c}\text { Cementitious Pavement } \\
\text { Materials }\end{array}$} & \multicolumn{2}{c}{ Average Temperature, ${ }^{\circ} \mathbf{C}$} & \multicolumn{2}{c}{ Average Humidity, \% } \\
\cline { 2 - 5 } & 7 Days & 28 Days & 7 Days & 28 Days \\
\hline Control & 8 & 7 & 91 & 91 \\
\hline 2\% sodium acetate & 5 & 6 & 91 & 90 \\
\hline $4 \%$ sodium acetate & 5 & 6 & 91 & 89 \\
\hline $6 \%$ sodium acetate & 5 & 6 & 91 & 89 \\
\hline
\end{tabular}

\subsection{Testing Procedures}

The experimental program was divided into four main sections: (1) microstructural analysis, (2) water absorption, (3) flexural strength, and (4) compressive strength.

The microstructure and the interaction between the added sodium acetate additive and concrete pavement were investigated by using scanning electron microscopy (SEM) [29]. Samples under all different curing conditions were studied to check the influence of curing conditions on treatment. A thin gold coating was applied to samples before testing under SEM to enhance their conductivity.

Water absorption was determined for all mixes after 28 days of curing following the guidelines of the British Standard BS 1881-122 [30]. The purpose of performing this test is to evaluate the permeability of concrete pavement after incorporating sodium acetate. Samples were dried in an oven for $48 \mathrm{~h}$ at $110^{\circ} \mathrm{C}$ before commencing the test and then they were immersed in water for different periods, and the difference in masses between dry and wet samples were recorded. Masses of samples were taken at the intervals of 0,30,60, $120,240,360,720,1440$ and $2880 \mathrm{~min}$.

Flexural strength test was performed after 7 and 28 days of curing, following the recommendations of the British Standard BS EN 1015-11 [31]. A 3400 Universal Testing Machine (Instron, Norwood, MA, USA) was used with a loading rate of $50 \mathrm{~N} / \mathrm{s}$ and with three-point loading frame.

Following the flexural strength testing, compressive strength was carried out using the same machine, following the guidelines of the British Standard BS EN 1015-11 [31]. The compressive strength test was carried out by using the loading rate of $9 \mathrm{~mm} / \mathrm{min}$. Figure 1 Illustrates a schematic diagram for the testing program carried out in this research.

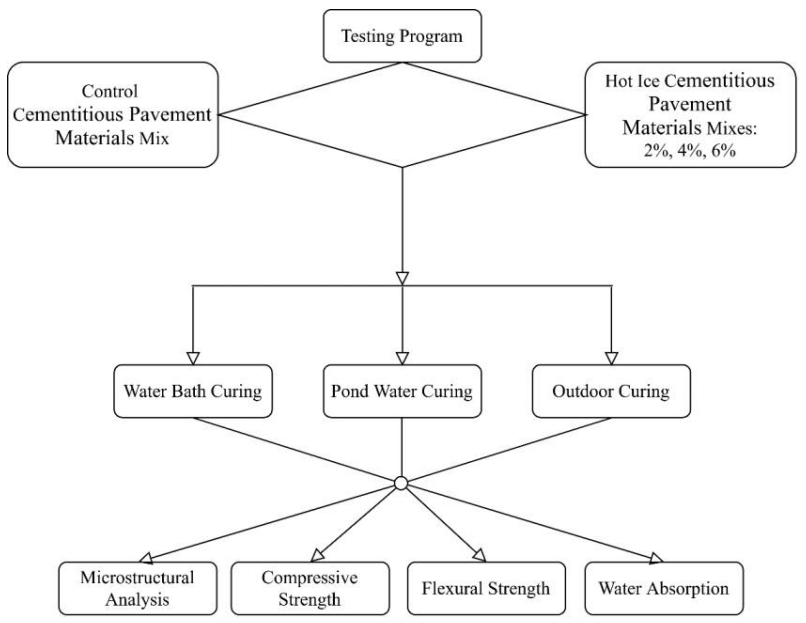

Figure 1. An overview of the experimental program. 


\section{Results and Discussion}

\subsection{Microstructural Analysis}

Changes in the morphology of the pore structure of the PCC pavement after the incorporation of sodium acetate and curing it in different environments were assessed by running the SEM analysis (Figure $2 \mathrm{a}-\mathrm{c}$ ). As illustrated in Figure $2 \mathrm{a}$, curing the treated PCC pavement samples in water resulted in the formation of sufficient sodium acetate crystals within the cement matrix. Forming such crystals will increase the presence of organosilicon bonds in the matrix. The presence of these bond worked on developing a dense microstructure with non-existent microcracks [8]. This might refer to the influence of organosilicon bonds in strengthening the interfacial area between aggregate and cement matrix and protecting them from debonding. It is witnessed from Figure $2 a$ that calcium silicate gel was formed with sufficient amounts, which is evidence for a normal hydration process that was not affected by the presence of the sodium acetate crystals. Also, the presence of calcium silicate gel is evident for a high strength development of concrete. Moreover, curing PCC pavement samples in water worked on boosting the hydration process and, at the same time, forming more organosilicon bonds, which resulted in the dense microstructure of concrete [6].

On the other hand, some microcracks were observed after the curing of treated PCC pavement in natural environment (outdoor) (Figure 2b). This might refer to the high demand of sodium acetate for water to form its crystals, which will be absorbed from the mixing water that is necessary to complete the hydration process. The absence of water during the curing period will hinder hydration and result in forming some microcracks [3,6]. Also, it is witnessed from Figure $2 b$ that fewer sodium acetate crystals were formed, which will result in the development of fewer organosilicon bonds in the matrix. The absence of organosilicon bonds might contribute to creating a scattered mixture and reducing the bonding that was observed in the water-cured mix (as shown in Figure 2a). Interestingly, a high distribution of ettringites was observed in the matrix, which is evidence for a retarded hydration. This can advance the propagation of microcracks within the mix.

Curing PCC pavement samples in pond water was observed to result in the development of low amounts of sodium acetate crystals, which in turn will create fewer organosilicon bonds inside the pores (Figure 2c). This can be attributed to the presence of impurities in the water during the hydration process that interfere with the development and growth of crystals. Also, a high distribution of microcracks was observed in the matrix. The formation of these microcracks may be also due to the presence of impurities in the pond water that hinders the hydration process and reducing the reaction between sodium acetate and silica in aggregate, which will contribute to forming fewer organosilicon bonds. Also, as seen in Figure 2c, ettringites are present densely distributed within the pores, which is evidence for the incomplete hydration process. This would result in the formation of more microcracks in the matrix. 

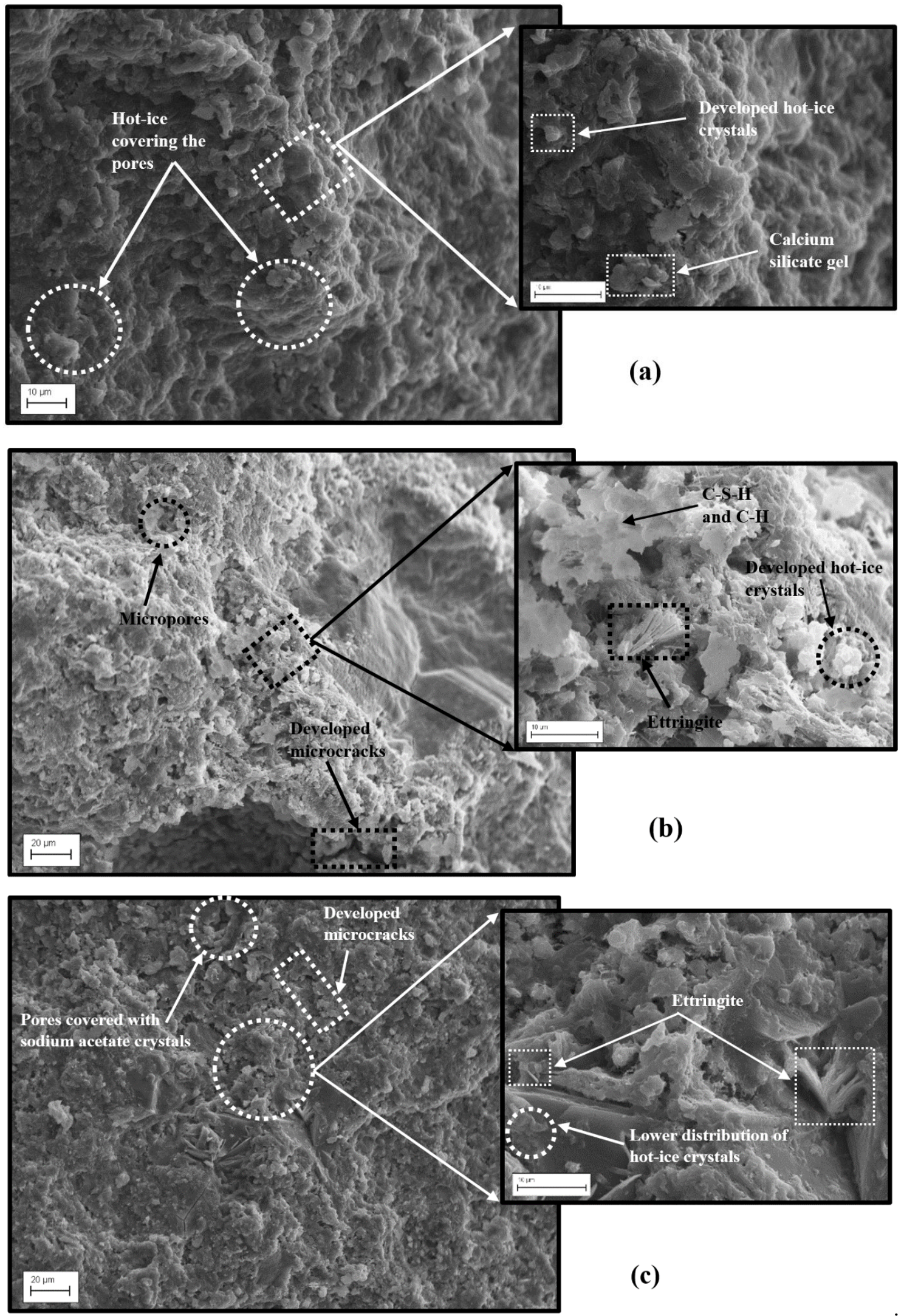

Figure 2. Microstructural analysis for PCC pavement treated with sodium acetate and cured in: (a) water bath, (b) natural environment (outdoor), and (c) pond water. 


\subsection{Water Absorption}

With the aim of assessing the performance of concrete pavement when subjected to wet environments, all specimens were tested for water absorption after 28 days of curing. As shown in Figure 3a-c, control samples absorbed the highest amount of water under all curing conditions-water bath, pond water and the natural environment. On the other hand, using sodium acetate additive resulted in a reduction of the water absorption rate under all curing conditions, though with varying levels depending on the additive dosage. The addition of $6 \%$ sodium acetate resulted in the lowest permeability among all mixtures under all curing conditions with maximum water absorption rates of $10 \%, 12 \%$, and $13 \%$ when cured in the water bath, natural environment and pond water, respectively. Conversely, adding $2 \%$ and $4 \%$ sodium acetate showed a modest/no enhancement in the impermeability of cementitious pavement materials, with water absorption rates in the vicinity of control under all curing conditions. Moreover, the addition of $2 \%$ sodium acetate caused a reduction of $6 \%$ and $5 \%$ in the water absorption of concrete when cured in water bath and natural environment, respectively (Figure 3a,b). Nevertheless, curing the $2 \%$ sodium acetate mix in pond water increased the permeability of concrete to $2 \%$ which is similar to the water absorption rate of the control sample (Figure 3c). In contrast, the addition of $4 \%$ sodium acetate contributed to a moderate reduction in water absorption of $11 \%, 9.5 \%$, and $2.5 \%$ when concrete was cured in a water bath, a natural environment and pond water, respectively.

Interestingly, it is evident, from Figure $3 \mathrm{a}-\mathrm{c}$ that the water absorption rate decreases with increasing added amount of sodium acetate. Still, the addition of $2 \%$ and $4 \%$ sodium acetate additives showed high water absorption rates that are close to control. This could be due to the formation of organosilicon bonds inside the matrix, as a result of the interaction between silica in sand and $-\mathrm{CH}_{3}$ group in the dissociated sodium acetate (after its reaction with water) [3]. These organosilicon bonds are characterised by their hydrophobic properties that work to fend off water from pores inside concrete, which will be reflected on the overall water absorption of the concrete $[3,25]$. Accordingly, increasing the added amount of sodium acetate leads to a reduction of water absorption rates of samples significantly, since more organosilicon bonds are formed.

On the other hand, pond water curing (Figure 3c) was noticed to produce higher water absorption rates than other curing conditions. This is attributable to the presence of impurities in the pond water that reduce the hydration process of cement and hinder the reaction between sodium acetate and silica in the aggregate.

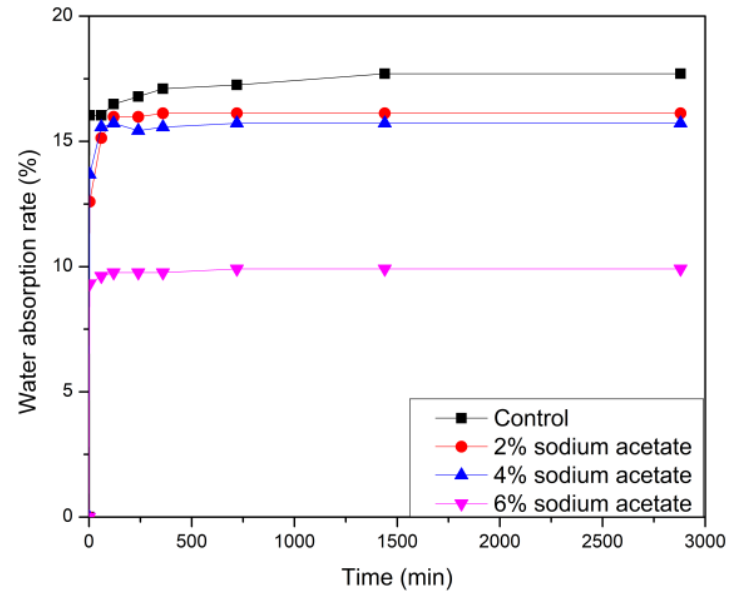

(a)

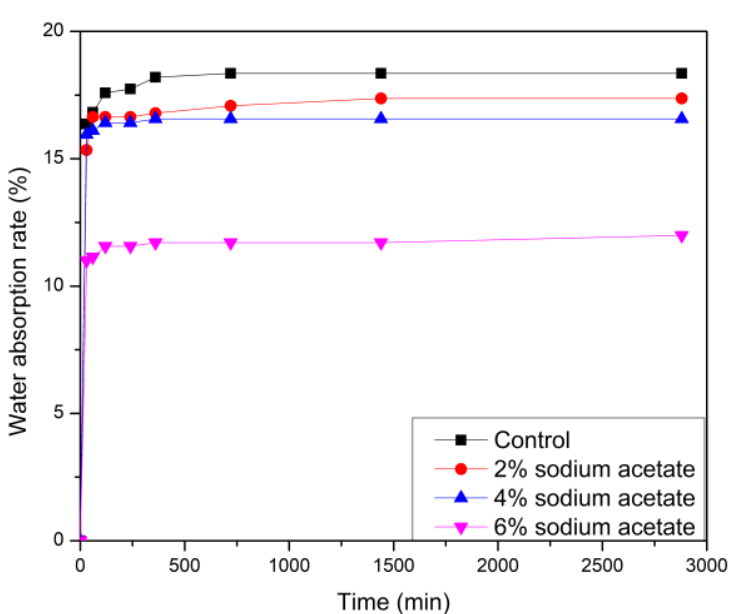

(b)

Figure 3. Cont. 


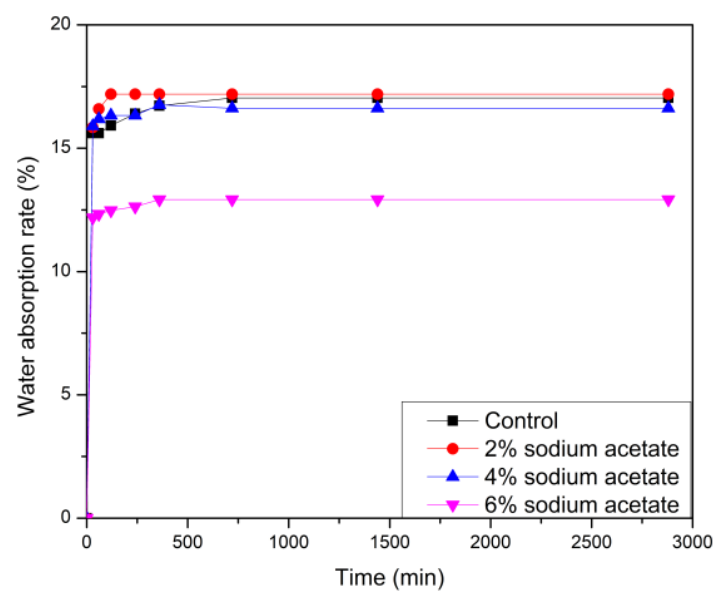

(c)

Figure 3. Water absorption rates PCC pavement after 28 days of curing in: (a) water bath, (b) natural environment (outdoor), and (c) pond water.

\subsection{Compressive Strength}

A comparison of the development of compressive strength after 7 days and 28 days of curing was done for all samples in order to evaluate the influence of the additives on the cementitious pavement materials. As highlighted in Figure $4 \mathrm{a}$, the addition of sodium acetate in $2 \%, 4 \%$ and $6 \%$ amounts showed a modest enhancement in the compressive strength of concrete pavement when cured in a water bath for 7 days. On the other hand, adding sodium acetate in the different percentages showed a significant enhancement in the strength when concrete pavement was cured in a natural environment after 7 days. Moreover, only the addition of $2 \%$ sodium acetate worked to increase the compressive strength of concrete pavement when cured in pond water, while the addition of $4 \%$ and $6 \%$ sodium acetate negatively affected the concrete pavement with a reduction of $9.5 \%$ and $8 \%$ in the strength when compared to control. The reduction noticed in the compressive strength of concrete pavement containing $4 \%$ and $6 \%$ sodium acetate and cured for 7 days in pond water could be due to the presence of a high amount of water at such AN early age. As observed by Al-Kheetan et al., sodium acetate helps increase the workability of concrete [3]. This increase in the workability accompanied by the formation of organosilicon bonds in the matrix can potentially hinder the hydration process of concrete at early ages, which negatively affects the compressive strength of the concrete [3,25]. Additionally, the presence of some impurities in pond water might also influence the hydration process of concrete, resulting in a strength reduction, whereas the addition of $2 \%$ sodium acetate did not reduce the strength of concrete, which is probably due to the small percentage of the added sodium acetate (fewer organosilicon bonds with sufficient/lower workability). When it comes to the 28 days curing period (Figure $4 \mathrm{~b}$ ), concrete showed a general reduction in compressive strength when cured in a water bath and an outdoors environment. A maximum reduction in compressive strength of $17 \%$ (compared to control) was observed after a $6 \%$ sodium acetate addition to concrete pavement when cured in a water bath. A minimum reduction of $2 \%$ in the strength was noticed when $2 \%$ sodium acetate is added to the materials and cured in an outdoors environment. However, curing concrete pavement in pond water resulted in a general increase in the compressive strength levels of $6 \%, 2 \%$ and $1 \%$ after the addition of $2 \%, 4 \%$ and $6 \%$ sodium acetate, respectively (compared to control). The generated reduction in compressive strength of concrete pavement after curing in water bath and outdoor environment (Figure $4 \mathrm{~b}$ ) could be attributed to the high presence of organosilicon bonds in cementitious composites, which are characterised by their hydrophobic properties $[8,23,25]$. The presence of cementitious composites in favourable curing conditions like a water bath and an outdoors environment would boost the formation of enough organosilicon bonds in the matrix that can potentially lead to repelling water outside the pores, which is necessary to complete the hydration process. 
The reduction of compressive strength is observed to grow with increasing added amount of sodium acetate from $2 \%$ to $6 \%$, which is evident for the influence of increasing the organosilicon bonds on cement paste/matrix. On the other hand, the increase in compressive strength after curing concrete pavement in pond water refers to the presence of high percentages of impurities that interfere with the formation of high quantities of organosilicon bonds in the matrices. Nevertheless, further research is needed to analyse the chemical composition of pond water and its effect on concrete.

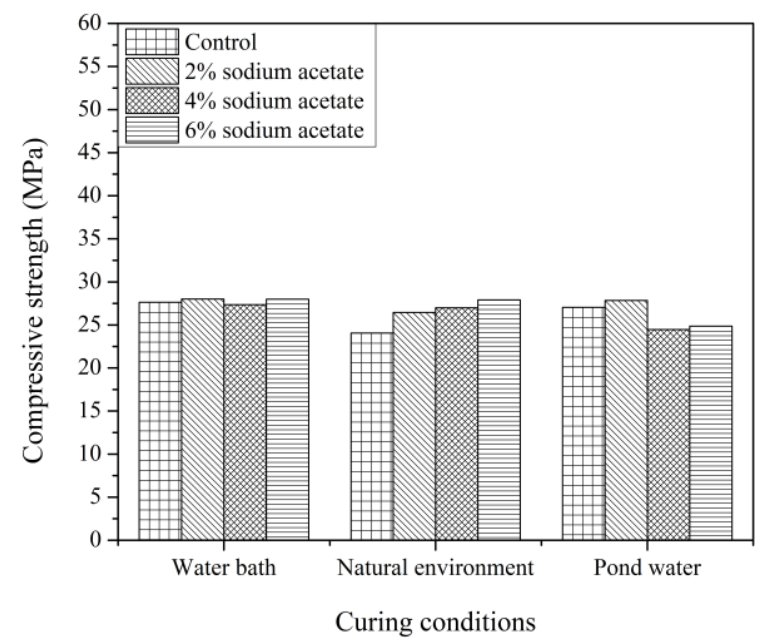

(a)

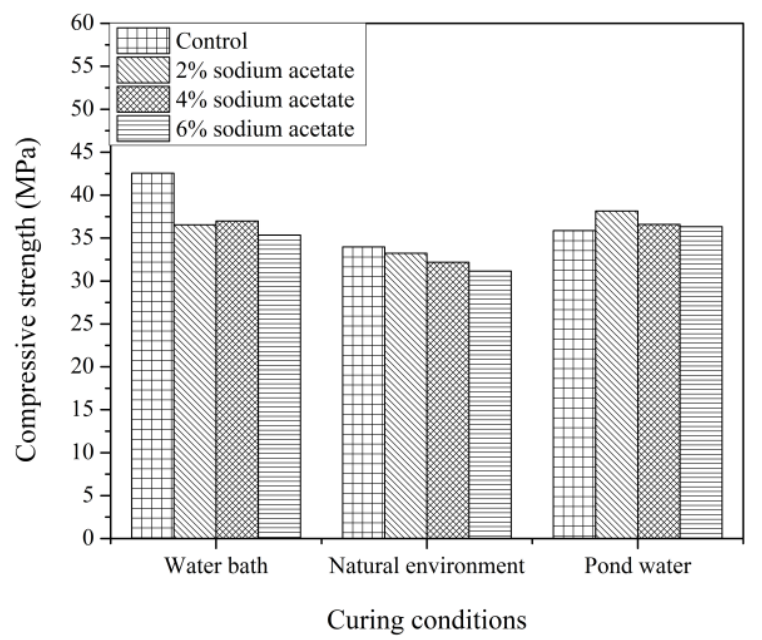

(b)

Figure 4. Compressive strength of PCC pavement after a curing period of: (a) 7 days and (b) 28 days.

\subsection{Flexural Strength}

The resistance of PCC pavement against deformation was assessed by conducting a flexural strength test at 7 and 28 days. As shown in Figure 5a, only the addition of $2 \%$ sodium acetate to concrete led to an increase in its flexural strength when cured under all curing conditions for 7 days, i.e., $6 \%, 46 \%$, and $4 \%$ increase in strength when cured in a water bath, outdoors environment and pond water, correspondingly. An increase of $15 \%$ and $25 \%$ were also noticed after the addition of $4 \%$ and $6 \%$ sodium acetate, respectively, to concrete pavement when cured in an outdoors environment (Figure 5a). On the other hand, a maximum reduction of $43 \%$ was noticed in the flexural strength of the $6 \%$ sodium acetate concrete pavement when cured in pond water. As stated previously, it is verified that $4 \%$ and $6 \%$ sodium acetate concrete pavement cured for 7 days under water bath and pond water condition suffered from a strength reduction when compared with control. This could be attributed to the impact of two joint factors: (1) the consumption of a high amount of water, at such early age, by the added sodium acetate compound in order to form hydrophobic organosilicon bonds, which in turn will lead to repelling the water necessary to continue the hydration process to the surface of cementitious composite and, (2) the incomplete hydration process at an early age (7 days). Moreover, adding $2 \%$ sodium acetate contributed to a significant increase in flexural strength, especially when concrete pavement is cured under favourable curing conditions like a water bath and an outdoors environment. The addition of a small percentage of sodium acetate $(2 \%)$ to concrete pavement will produce fewer organosilicon bonds compared to those formed when high percentages of sodium acetate are added to mixtures. The ability of the formed organosilicon bonds, in the case of $2 \%$ sodium acetate, to repel the water that is necessary to continue the hydration process will be less than those formed after adding $4 \%$ and $6 \%$ sodium acetate $[8,23,25]$. As illustrated in Figure $5 \mathrm{~b}$, after 28 days of curing of sodium acetate concrete pavement in a water bath a general reduction was observed, along with another modest reduction for the $2 \%$ sodium acetate concrete pavement when cured in an outdoors environment. Curing cementitious composites in a water bath will 
create a suitable environment for the added sodium acetate to form high amounts of hydrophobic organosilicon bonds that can lead to a reduction in the bonding strength between hydrated cement and sand. This will be negatively reflected in the overall flexural strength. In contrast, curing the sodium acetate concrete pavement in pond water improved the flexural strength (regardless of the amount of sodium acetate added). Furthermore, the addition of $2 \%$ sodium acetate to concrete that was cured in pond water worked to produce concrete with the highest flexural strength.

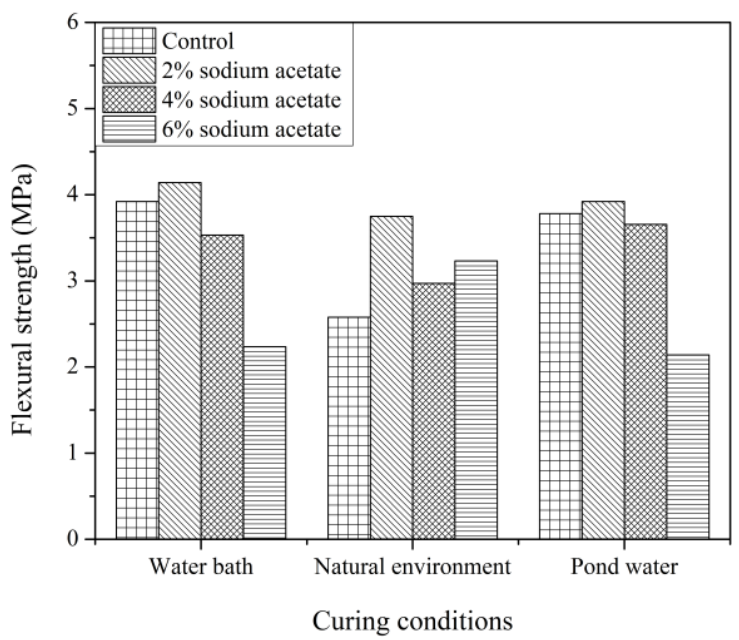

(a)

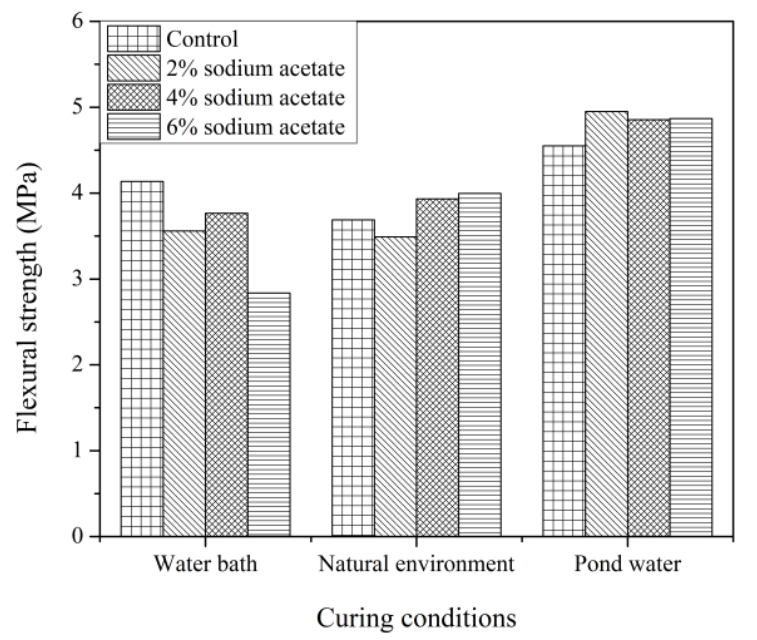

(b)

Figure 5. Flexural strength properties of PCC pavement when cured for: (a) 7 days and (b) 28 days.

On the other hand, adding $4 \%$ and $6 \%$ of sodium acetate to concrete pavement worked on increasing the flexural strength when cured in an outdoors environment. The increase in the strength of sodium acetate concrete pavement when present in pond water is evidently due to the presence of contaminants in water, which might influence the formation of organosilicon bonds (hinder its formation in large quantities). The increase in the strength of $4 \%$ and $6 \%$ sodium acetate concrete pavement when cured in an outdoors environment might be attributed to the curing environment that is not governed by the presence of water. The absence of water during curing might potentially lead to the formation of fewer organosilicon bonds, which will decrease the flexural strength impact.

\section{Conclusions}

This studied aimed to enhance PCC pavement properties by integration of sodium acetate under various curing conditions including an outdoors environment, a water bath and pond water. Accordingly, the following conclusions can be drawn from the work conducted in this study:

(1) Adding sodium acetate to concrete pavement resulted in a maximum reduction of $44 \%$, when $6 \%$ sodium acetate was used and the samples were cured in a water bath.

(2) An increase of $6 \%$ in the compressive strength of concrete pavement after 28 days of curing in pond water was observed when $2 \%$ sodium acetate was added. The same trend was noticed in compressive strength when concrete pavement is cured in a water bath and an outdoors environment for 7 days.

(3) The presence of high levels of organosilicon bonds in concrete (after the addition of sodium acetate) worked to reduce the bonds between cement and sand, which negatively affected compressive strength of concrete at the age of 7 days.

(4) A reduction of $43 \%$ was noticed in the flexural strength of the $6 \%$ sodium acetate concrete when cured in pond water after 7 days of curing, which refers to the formation of high levels of organosilicon bonds in the matrix. 
(5) A significant increase in flexural strength was observed in sodium acetate concrete pavement after 28 days of curing in pond water, which is consistent with the compressive strength outcomes.

Author Contributions: Methodology, visualization, conceptualization, formal analysis, M.J.A.-K., writing—original draft, M.J.A.-K., S.H.G., S.A., M.M.R. writing—review and editing, M.J.A.-K., S.H.G., M.C., J.B., S.A., M.M.R.; resources, conceptualization, investigation, writing-original draft, S.H.G.; investigation, S.A.; investigation, methodology, resources, M.M.R. All authors have read and agreed to the published version of the manuscript.

Funding: This research did not receive any specific grant from funding agencies in the public, commercial, or not-for-profit sectors.

Data Availability Statement: The data presented in this study are available on request from the corresponding author. The data are not publicly available due to privacy.

Acknowledgments: The authors wish to acknowledge undergraduate students Kyle Fletcher and Kristoph Goma for their help in the laboratory work.

Conflicts of Interest: The authors declare no conflict of interest.

\section{References}

1. Mataei, B.; Nejad, F.M.; Zakeri, H. Pavement maintenance and rehabilitation optimization based on cloud decision tree. Int. J. Pavement Res. Technol. 2021, 14, 740-750. [CrossRef]

2. Al-Kheetan, M.; Byzyka, J.; Ghaffar, S. Sustainable valorisation of silane-treated waste glass powder in concrete pavement. Sustainability 2021, 13, 4949. [CrossRef]

3. Al-Kheetan, M.J.; Rahman, M.M. Integration of anhydrous sodium acetate (ASAc) into concrete pavement for protection against harmful impact of deicing salt. JOM 2019, 71, 4899-4909. [CrossRef]

4. Ghaffar, S.H.; Burman, M.; Braimah, N. Pathways to circular construction: An integrated management of construction and demolition waste for resource recovery. J. Clean. Prod. 2020, 244, 118710. [CrossRef]

5. Snelson, D.G.; Kinuthia, J.M.; Davies, P.A.; Chang, S.R. Sustainable construction: Composite use of tyres and ash in concrete. Waste Manag. 2009, 29, 360-367. [CrossRef] [PubMed]

6. Al-Kheetan, M.J.; Rahman, M.M.; Chamberlain, D.A. Development of hydrophobic concrete by adding dual-crystalline admixture at mixing stage. Struct. Concr. 2018, 19, 1504-1511. [CrossRef]

7. Al-Kheetan, M.J.; Rahman, M.M.; Chamberlain, D.A. Moisture evaluation of concrete pavement treated with hydrophobic surface impregnants. Int. J. Pavement Eng. 2019, 21, 1746-1754. [CrossRef]

8. Al-Kheetan, M.J.; Ghaffar, S.H.; Madyan, O.A.; Rahman, M.M. Development of low absorption and high-resistant sodium acetate concrete for severe environmental conditions. Constr. Build. Mater. 2020, 230, 117057. [CrossRef]

9. Al-Kheetan, M.J.; Rahman, M.M.; Chamberlain, D.A. A novel approach of introducing crystalline protection material and curing agent in fresh concrete for enhancing hydrophobicity. Constr. Build. Mater. 2018, 160, 644-652. [CrossRef]

10. Tyrer, M.; Cheeseman, C.R.; Greaves, R.; Claisse, P.A.; Ganjian, E.; Kay, M.; Churchman-Davies, J. Potential for carbon dioxide reduction from cement industry through increased use of industrial pozzolans. Adv. Appl. Ceram. 2010, 109, 275-279. [CrossRef]

11. Bastani, M.; Behfarnia, K. Application of alkali-activated slag in roller compacted concrete. Int. J. Pavement Res. Technol. 2020, 13, 324-333. [CrossRef]

12. Gartner, E. Industrially interesting approaches to "low- $\mathrm{CO}_{2}$ " cements. Cem. Concr. Res. 2004, 34, 1489-1498. [CrossRef]

13. Marathe, S.; Mithanthaya, I.R.; Mithun, B.M.; Shetty, S.; Akarsh, P.K. Performance of slag-fly ash-based alkali activated concrete for paver applications utilizing powdered waste glass as a binding ingredient. Int. J. Pavement Res. Technol. 2020, 14, 196-203. [CrossRef]

14. Worrell, E.; Price, L.; Martin, N.; Hendriks, C.; Meida, L.O. Carbon dioxide emissions from the global cement industry. Annu. Rev. Energy Environ. 2001, 26, 303-329. [CrossRef]

15. Aghayan, I.; Khafajeh, R.; Shamsaei, M. Life cycle assessment, mechanical properties, and durability of roller compacted concrete pavement containing recycled waste materials. Int. J. Pavement Res. Technol. 2020, 14, 595-606. [CrossRef]

16. Ekpo, D.U.; Fajobi, A.B.; Ayodele, A.L. Response of two lateritic soils to cement kiln dust-periwinkle shell ash blends as road sub-base materials. Int. J. Pavement Res. Technol. 2020, 14, 550-559. [CrossRef]

17. Sereewatthanawut, I.; Prasittisopin, L. Environmental evaluation of pavement system incorporating recycled concrete aggregate. Int. J. Pavement Res. Technol. 2020, 13, 455-465. [CrossRef]

18. Onyelowe, K.; Igboayaka, C.; Orji, F.; Ugwuanyi, H.; Van, D.B. Triaxial and density be-haviour of quarry dust based geopolymer cement treated expansive soil with crushed waste glasses for pavement foundation purposes. Int. J. Pavement Res. Technol. 2019, 12, 78-87. [CrossRef] 
19. García, N.M.; Zapata, L.E.; Suarez, O.; Cabrera-Ríos, M. Effect of fly ash and nanosilica on compressive strength of concrete at early age. Adv. Appl. Ceram. 2014, 114, 99-106. [CrossRef]

20. Ghaffar, S.H.; Al-Kheetan, M.; Ewens, P.; Wang, T.; Zhuang, J. Investigation of the interfacial bonding between flax/wool twine and various cementitious matrices in mortar composites. Constr. Build. Mater. 2020, 239, 117833. [CrossRef]

21. Chougan, M.; Marotta, E.; Lamastra, F.R.; Vivio, F.; Montesperelli, G.; Ianniruberto, U.; Ghaffar, S.H.; Al-Kheetan, M.J.; Bianco, A. High performance cementitious nanocomposites: The effectiveness of nano-graphite (nG). Constr. Build. Mater. 2020, $259,119687$. [CrossRef]

22. Albar, A.; Chougan, M.; Al-Kheetan, M.J.; Swash, M.R.; Ghaffar, S.H. Effective extrusion-based 3D printing system design for cementitious-based materials. Results Eng. 2020, 6, 100135. [CrossRef]

23. Al-Kheetan, M.J.; Rahman, M.M.; Ghaffar, S.H.; Jweihan, Y.S. Comprehensive investigation of the long-term performance of internally integrated concrete pavement with sodium acetate. Results Eng. 2020, 6, 100110. [CrossRef]

24. Al-Otoom, A.; Al-Khlaifa, A.; Shawaqfeh, A. Crystallization technology for reducing water permeability into concrete. Ind. Eng. Chem. Res. 2007, 46, 5463-5467. [CrossRef]

25. Al-Kheetan, M.J.; Rahman, M.M.; Chamberlain, D.A. Fundamental interaction of hydrophobic materials in concrete with different moisture contents in saline environment. Constr. Build. Mater. 2019, 207, 122-135. [CrossRef]

26. Al-Kheetan, M.J.; Rahman, M.M.; Balakrishna, M.N.; Chamberlain, D.A. Performance enhancement of self-compacting concrete in saline environment by hydrophobic surface protection. Can. J. Civ. Eng. 2019, 46, 677-686. [CrossRef]

27. Bang, S.S.; Johnston, D. Environmental effects of sodium acetate/formate deicer, Ice Shear ${ }^{\mathrm{TM}}$. Arch. Environ. Contam. Toxicol. 1998, 35, 580-587. [CrossRef] [PubMed]

28. British Standards Institution. BS EN 998-2, Specification for Mortar for Masonry. Masonry Mortar; British Standard Institute (BSI): London, UK, 2016.

29. Lamastra, F.R.; Chougan, M.; Marotta, E.; Ciattini, S.; Ghaffar, S.H.; Caporali, S.; Vivio, F.; Montesperelli, G.; Ianniruberto, U.; Al-Kheetan, M.J.; et al. Toward a better under-standing of multifunctional cement-based materials: The impact of graphite nanoplatelets (GNPs). Ceram. Int. 2021, 47, 20019-20031. [CrossRef]

30. British Standards Institution. BS EN 1881-122, Testing Concrete. Method for Determination of Water Absorption; British Standard Institute (BSI): London, UK, 2011.

31. British Standards Institution. BS EN 1015-11, Methods of Test for Mortar for Masonry. Determination of Flexural and Compressive Strength of Hardened Mortar; British Standard Institute (BSI): London, UK, 2019. 